\title{
Gendered patterns of interaction: A Foucauldian discourse analysis of couple therapy
}

Olga Sutherland

University of Guelph

Andrea LaMarre

University of Guelph

Carla Rice

University of Guelph

Laura Hardt

University of Guelph

Nicole Jeffrey

University of Guelph

This is a post-peer-review, pre-copyedit version of an article published in Contemporary Family Therapy. The final authenticated version is available online at: https://doi.org/10.1007/s10591-016-9394-6

\section{Recommended citation:}

Sutherland, O., LaMarre, A., Rice, C., Hardt, L., \& Jeffrey, N. (2016). Gendered patterns of interaction: A Foucauldian discourse analysis of couple therapy. Contemporary Family Therapy, 38(4), 385-399.

https://doi.org/10.1007/s10591-016-9394-6 


\section{Gendered Patterns of Interaction: A Foucauldian Discourse Analysis of Couple Therapy}

Olga Sutherland, Andrea LaMarre, Carla Rice, Laura Hardt, Nicole Jeffrey

\section{Abstract}

In recent years, there has been a rapid increase in attention to gender and gender-based inequalities in family therapy. Despite this, there is a dearth of empirical work that examines how gendered inequalities intersecting with other axes of privilege/oppression are maintained within families, including in the therapeutic context. In this study, we used Foucauldian discourse analysis to examine how gendered power is produced and reproduced circularly or through recurrent patterns of interaction in couple therapy. We identified gendered discourses and assumptions informing partners' constructions of their gendered selves and relationships. We highlight the complexity and intersectionality of gendered subjectivities and relations in contemporary Canadian couples involved in heterosexual relationships. Although women in this study contest their oppression and exhibit agency to negotiate who they are in general and in relation to men, they simultaneously continue to occupy subordinate positions in a gender order that is culturally and interactionally allocated to them. We discuss implications for family therapy practice. 


\section{Keywords}

Gender; Power; Patterns of Interaction; Foucauldian discourse analysis; Intersectionality

\section{Introduction}

There is a consensus in the field of family therapy that gender and other markers of social difference matter (e.g., Almeida et al. 2008; Knudson-Martin 2013; McGoldrick and Hardy 2008). Despite general recognition of the importance of paying attention to social differences and power differentials in families, many therapists remain uncertain about how to address these issues, both in practice and curriculum (e.g., Williams et al. 2013; Winston and Piercy 2010). Although therapists may be aware of gender stereotypes and sexist assumptions, they may struggle to recognize them in concrete social interactions (Hernández et al. 2005; KnudsonMartin 2013).

One way to support therapists in enhancing practical skills for addressing gender and power in family systems is to offer detailed empirical analyses of family interactions, including in the context of therapy. Feminist-informed analyses could help practitioners recognize sexist premises and dynamics of dominance/subordination and offer opportunities to reflect on how these can be undermined and transformed. Accordingly, we empirically identified techniques of power mobilized within families to produce gendered subjects and relations suitable to a sexist social order. In particular, we sought to identify sexist ideology (discourses and assumptions) in couples' interactions, such as constructions of gender stereotypes and differences as real, natural, and commonsense. 
To accomplish this, we adopted social constructionist and poststructural perspectives and envisioned gender as socially constructed, context-bound, and fluid (e.g., Butler 1993; Hare-Mustin and Marecek 1990; Hollway 1998; Knudson-Martin 2013). We assumed that gender is not a fixed property of people but rather an active "doing" of a recognizable gender identity that acquires and changes its form and meaning through social practices and relations. For us, there is no gender beyond and outside of its discursive production and negotiation (i.e., through people's routine use of language, including speech, bodily gestures, and other forms of bodily self-expression). The study is also based on the assumption that gender-based power differentials are maintained, at least in part, through patterns of interaction within families, with power relations simultaneously shaping the precise nature of these interactions (Giddens 1979; Keenan 2007; St. George and Wulff 2014). We theorized and analyzed power as reproduced and sustained through recurrent and reciprocal positioning of family members in dominant gender-differentiated discourses. The reproduction of gender and gendered power implies its maintenance, contestation, and transformation. Family members routinely, though not necessarily consciously, perform and transgress normative gender in their interactions and, in so doing, support male dominance and female subordination (Butler 1990).

In light of these ideas, we examined "the recurrent splitting between men and women of gender specified characteristics" (Hollway 1998, p. 224) as both discursive and systemic accomplishment, with the latter being concerned with partners' reciprocally linked positions in interaction. We used the Pathologizing Interpersonal Patterns (PIPs) and Healing 
Interpersonal Patterns (HIPs) framework (Tomm 1991, 2014a, b). To clarify, we offer not an analysis of the PIPs/HIPs systemic framework, but rather a study informed by this framework. We begin by providing an overview of the PIPs and HIPs model, followed by a description of the methodology and procedures used in our study. We then present the results and conclude by discussing study implications for therapy research and practice.

\section{The PIPs and HIPs Framework}

The PIPs and HIPs framework was developed by Karl Tomm (1991) and his colleagues in the Family Therapy Program at the University of Calgary in Canada. It was informed by a range of theoretical influences, including structural, Bowenian, and communication approaches to family therapy (Tomm 2014a). Reluctant to use the Diagnostic and Statistical Manual of Mental Disorders, 3rd Edition (DSM-III, American Psychiatric Association 1980) to assess family dynamics because of the potential stigmatizing effects on clients of psychiatric labeling, Tomm developed a systemic approach to psychiatric assessment. He saw this as a useful tool for decision-making concerning public funding allocation and for addressing social justice concerns associated with labeling. In assessing family and individual functioning, Tomm focused on patterns of interaction. The two main patterns are PIPs and HIPs, though other patterns can also be distinguished, such as deteriorating, transforming, and wellness patterns (Tomm 1991). He explained that the PIPs and HIPs model could assist therapists in identifying sequences of actions (e.g., thoughts, beliefs, expectations, emotions, behaviors) that promote, and those that infringe upon, clients' wellbeing. Problematic patterns (PIPs) may have pathologizing effects on family members engaged in them. An example of a 
PIP is criticizing coupled with defending. A father may criticize a teenage son for not doing the chores and the son may defend his actions. As criticism and defensiveness are recurrently enacted, family members' responses become circularly "coupled"-criticism invites defensiveness and defensiveness invites further criticism, etc. A corresponding HIP may be selective noticing of competence coupled with increased acts of competence. The father would notice and comment on the times when the son spontaneously completed chores triggering future acts of compliance in the son. In contrast to the pathologizing effects of PIPs, HIPs tend to have beneficial effects. In the case of the above-mentioned HIP, beneficial effects may include increased respect for the other or self-confidence (Tomm 1991).

In response to a growing awareness of issues of difference and social justice in family therapy in the past decade, Tomm and colleagues have sought to incorporate analyses of culture and power into the PIPs and HIPs framework (Schultz Hall and Sametband 2014; St. George and Wulff 2014; St. George et al. 2015; Wulff et al. 2015). Specifically, they augmented the HIPs and PIPs model with sociocultural interpersonal patterns, such as those marked by gender, race, and class (Schultz Hall and Sametband 2014; St. George and Wulff 2014); and proposed that larger social structures are formed and maintained through patterns of interaction. Family interactions can be seen as shaped by broader relations of power and, in turn, as reinforcing and undermining these relations (e.g., Giddens 1979; St. George and Wulff 2014). Accordingly, the sociocultural PIPs and HIPs model can help facilitate changes in both family relations and social structures (Keenan 2007). 
The social structure that is of particular concern to proponents of the HIPs and PIPs model is the global dominance of men over women. Gendered PIPs (GPIPs), such as dominating coupled with submitting, enable and justify male privilege and dominance (Schultz Hall and Sametband 2014). They involve recurrent sequences of actions featuring rigid, essentialist, or binary notions of gender (e.g., there are two genders only: masculine and feminine; women are like $\mathrm{X}$, men are like $\mathrm{Y}$ ). GPIPs are formed and sustained when family members reciprocally occupy the asymmetrical (dominant/submissive) gendered positions in a hierarchical gender order. Hegemonic masculinity (i.e., practices of enactment of masculine dominance over women) can become circularly linked with emphasized femininity (i.e., practices of submitting to men or accommodating to their interests and needs; Connell and Messerschmidt 2005). If gendered and other PIPs draw on and reinforce narrow, normative assumptions concerning gender, gendered HIPs (GHIPs; e.g., honoring of concerns and wishes of the other coupled with voicing of ideas and concerns) challenge stereotypes and foster expressions of gender plurality and equality. The central task of therapy informed by the GPIPs and GHIPs model is to assist families in challenging rigid assumptions concerning gender, exploring alternative nonnormative gender identities, and moving away from hierarchical reciprocity toward balanced reciprocity or equality (Schultz Hall and Sametband 2014). What makes patterns "gendered" is that through the enactment of these patterns, partners constitute each other as gendered subjects. Thus, the construction and negotiation of gendered subjectivities (and identities) are at the core of the GPIPs/GHIPs (Schultz Hall and Sametband 2014). 
Other major dimensions of social difference (e.g., class, race, ethnicity, sexuality, ability, or age) may intersect with gender and enable or discourage certain interactional positions and the reciprocal link between them. An intersectional perspective offers an antidote to accounts that homogenize social categories or overlook the complexity and variability of experience within categories (Anthias 2012). It presupposes that social differences and divisions are mutually constitutive and that interacting oppressions produce specific entitlements and oppressions (Collins 1990; Crenshaw 1991). Intersectionality scholars critique the propensity to study only the most privileged members of subordinate groups (e.g., white, middle-class, and heterosexual women) and to ignore experiences of individuals with multiple subordinate statuses (e.g., racialized, working class, and queer women; Cole 2009; Warner and Shields 2013). While "intersectionality" has become an increasingly common term used to describe research that analyzes the intersecting effects of social differences, intersectionality scholars argue that researchers taking this approach must also orient to finding solutions to problems of social inequality surfaced in their research.

An intersectional framework has become well established across disciplines, particularly in gender and critical race studies, and has recently been applied to family therapy (e.g., Butler 2015; McDowell and Hernández 2010; McGeorge et al. 2014; Watts-Jones 2010). Informed by an intersectional lens, family therapists consider the interplay of power relations and complexity of people's experiences of oppression (Butler 2015). Rather than considering gender as a stand-alone category, they analyze gender in combination with other differences and consider both the 
privileges and oppressions afforded by intersecting identities. However, given that we did not have access to the demographic information and could not know social differences other than those spoken by the couples, we could not offer a comprehensive intersectional analysis. Also, in an attempt to make the analysis more manageable, we had to be strategic and focus on the categories that we deemed most relevant to our research focus (Christensen and Jensen 2012; McCall 2005). Considering that gendered power may function in distinct ways from classed or raced power (Yuval-Davis 2006), we decided to provisionally retain the distinctiveness of gender. While centering gender, we make interpretive claims concerning gender's intersections with other social categories, to the extent allowed by the empirical evidence. Our analysis moves beyond focusing on gender as a discrete category to considering how gender interacts and overlaps with other "axes" of power and difference (in this case, sexuality, class, age, geography, and ability). We do acknowledge, however, that there are likely other spaces to which participants belong that may impact their gendered and relational experiences beyond that which we were able to empirically "access". To clarify how power differentials are perpetuated through gendered patterns of interaction, we turned to poststructuralist thought, particularly the work of Michel Foucault and an approach to the study of discourse inspired by Foucault, namely Foucauldian discourse analysis (FDA; Arribas-Ayllon and Walkerdine 2008; Parker 1992; Willig 2013).

\section{Methodology}

Critical discourse analyses, including FDA, offer a sophisticated theory to understand the link between discourse and social structure (see Fairclough et al. 2011; Wodak and Meyer 2016). The term "discourse" is 
used variably within critical approaches to discourse analysis and generally refers to "broad constitutive systems of meaning" (Sunderland 2004, p. 6) or different ways of understanding the world (Fairclough 2012). Dominant discourses tend to advance perspectives that legitimize and support existing power relations and social structures (Parker 1992; van Dijk 2013). Introduced to Anglo-American psychology in the late 1970s (Willig 2013), Foucault's perspective on discourse presupposes the idea that meaningmaking is constructive and regulatory-it produces and delimits objects and subjects it names (Arribas-Ayllon and Walkerdine 2008; Foucault 1972, 1982). Phenomena can only be understood with reference to discourses in a specific cultural and historical period. It is thus discourse, rather than the person who speaks it, that produces knowledge. Foucault's conception of subjectivity as discursive and as "precarious, contradictory and in process" challenges the conventional notion of a unified and stable subject (Weedon 1987, p. 33). Foucault (1991a) conceptualized power as pervasive, socially distributed, and discursive, rather than as a tool consciously used by individuals or groups. Power is not something that people possessinstead, it circulates throughout social relations and constitutes people into certain kinds of subjects suitable to a prevailing political order. As people interact in society, they deploy, negotiate, and resist dominant and alternative discourses, alternately reinforcing, (re)inscribing, and reconfiguring power. Foucauldian discourse analysts often seek to make explicit this constructive dimension of power/discourse.

Discourses do not determine human conduct (Foucault 1982) but make available certain subject positions vis-à-vis others (e.g., dutiful daughter, family provider). A subject position is a way of understanding self 
and other or "a location for persons within a structure of rights and duties for those who use that repertoire [or discourse]" (Davies and Harré 1999, p. 35). Discourses constrain subjectivity by setting parameters on possibilities for meaning and action for those assuming subject positions. From a poststructural perspective, power often works outside of people's awareness and cannot be explained in terms of active choice (i.e., as individuals choosing to become subjects or objects of power practices) (e.g., Lazar 2005). At the same time, we do not endorse a deterministic perspective on human subjectivity as being void of agency or ability to "maneuver" within, destabilize, and transform social norms and structures. In support of this latter point, Butler (2004) remarked:

Transformation is produced by the play of forces, some of which are importantly unconscious, working through bodily means, so that when creativity takes place and something new is inaugurated, it is the result of an activity that precedes the knowing subject, but is not, for that reason, fully external to the subject. Something that precedes me constitutes who I am, and this paradox gives articulation to a conception of the subject irreducible to consciousness. (p. 194)

From this perspective, social structures do not act on subjects; rather, subjects reflexively reproduce structures through their everyday conduct (e.g., see Boden and Zimmerman 1991). Subjectivity is simultaneously constrained and agentic and these dimensions cannot be meaningfully separated.

Some scholars have explored how subjectivity, gender, race, and family relations are discursively produced (see Avdi and Georgaca 2007). 
However, family therapy is yet to fully take advantage of critical discourse analyses (Avdi and Georgaca 2007; Tseliou 2013) in the study of intersectional differences and inequalities. Critical discourse analyses can help unmask how power may operate in family interactions and supply concrete examples of how sexist ideology can be maintained, contested, and transformed through family and therapy discourse. Such analyses can offer therapists nuanced and context-sensitive knowledge of gender positions, norms, and relations intrinsic to a particular culture or community. This knowledge can, in turn, help therapists transcend stereotypical and oversimplified notions of gender as a stable or unified category.

\section{Data and Procedures}

The data for this study come from a larger study on gender and discourse in couple therapy involving heterosexual couples. In the larger study (Sutherland et al. 2016), the authors conducted a micro-oriented discursive psychological analysis of couple therapy sessions to explore how language is used in couple interactions to justify inequality. Here, we use a macro-oriented discursive lens to identify which gendered discourses are used to constitute couple interactions and partners' subjectivities in the same sessions. Given our concern with how cultural ideology shapes and constrains partners' meanings and responses in their relations, recorded sessions of couple therapy in which these discussions and interactions occur comprised the most suitable source of data. The data were collected between 2009 and 2013 at a university-based family therapy training center in Canada. At this training center, student-therapists learn to offer systemic and postmodern therapies to ethnically, racially, and socio-economically diverse clients under clinical faculty supervision. Routinely scheduled 
sessions are video-recorded for supervision purposes. Sessions for which mutual (clients' and therapists') consent is received are archived for research purposes. Upon approval by the university's Research Ethics Board, recordings were converted into an audio format to further preserve participant confidentiality.

One undergraduate and two graduate students conducted the initial data selection and sorting. They reviewed 30 sessions with 13 different clients, of which seven were couple therapy sessions. They selected three sessions out of seven for a more detailed discursive analysis. These three sessions were deemed to have the most potential to highlight both PIPs/HIPs and gendered dynamics of power, given that female partners in these sessions contested gender inequalities (e.g., unequal distribution of domestic responsibilities) and male partners responded to accusations of unfair conduct. Each of the selected sessions involved a different married heterosexually presenting couple. Feminist authors have long suggested that heterosexual relationships comprise the primary site of women's subordination (e.g., Ingraham 2006; Sharp and Keyton 2016), which made the analysis of interactions of heterosexual couples particularly salient. We selected excerpts from the three sessions ranging in length from 10 to 20 min and transcribed these excerpts using standard orthography. Demographic data were not collected concurrently with recorded data and this may have influenced our results. We could have drawn additional or different conclusions, for example, concerning race and its intersection with gender, if we were aware of how participants were racially positioned. While acknowledging potential interpretive and political benefits of having access to such demographic data, our lack of access to these data was 
also beneficial in some ways. It helped us avoid assuming that, just because someone self-identifies as a "woman" or as "heterosexual," these categories automatically be (equally) relevant and salient at any given point in interaction (e.g., Edwards 1998).

The first and second authors (a family therapy faculty member and a family relations doctoral student) reviewed selected excerpts through the GPIPs/GHIPs framework, identifying patterns of interaction in the data. They then used Willig's (2013) six stages of FDA to analyze the data. The third author (a gender studies faculty member) reviewed, revised, and edited this analysis. First, we identified relevant discursive constructions of intimate relationships and partner roles around a wide range of topics (childcare, sexuality, parenting, etc.), which Willig calls "objects of study". We considered both direct and indirect references; for example, the expression "he was not there for me" may be an example of an indirect reference to what one is like as a partner, whereas "we have a close connection" directly refers to the object of study, in this case, the relationship. Next, we explored how couple relationships were constructed differently across and within sessions. Here, we focused on identifying discourses informing how relationships are understood and described.

Our next step was to ask "what is gained from constructing the object in this particular way?" (Willig 2013, p. 138), as a way of reflecting on the sociopolitical implications of generated versions of relationships. Following this, we identified subject positions within discourses and explored their "coupling", according to the systemic PIPs and HIPs model. We then investigated the link between discourses and situated practices. This entailed (a) exploring how discourse plays a normalizing and regulatory 
role, and (b) reflecting on how discourses encourage certain ways of relating and discourage others. Finally, we examined how discourse forms gendered subjectivity through reciprocally linked subject positions. For instance, shifting, multiple, and even contradictory forms of masculinity, femininity, and amalgamations of the two may be involved in positioning self and other in a gender-based dominance/subordination pattern of interaction. Although we gave analytic priority to within-couple power dynamics, we peripherally attended to interactions between couples and therapists. Unfortunately, our analyses are limited in illustrating how GPIPs can be disrupted in therapy, mainly because therapists in our sample only minimally addressed gendered and other power disparities.

Aligning our analysis with the interpretive nature of FDA, we attended to how our own subjectivities and social situatedness may have influenced the research process and its outcomes as we selected and analyzed the data (Fairclough et al. 2011). We consider our social positioning to be relevant in writing this article. We are an interdisciplinary group of Canadian scholars with backgrounds in couple and family therapy, gender studies, social and counselling psychology, and family relations. We are somewhat diversely located (e.g., white, middle-class, queer and heterosexual, single and partnered, able-bodied and disability identified, one of us is a firstgeneration immigrant and another has working class roots and Indigenous kin). Our social locations helped us recognize certain dynamics, such as those related to gender and sexuality, but may have led us to overlook other structures of power, such as those related to race and ethnicity.

Our intention in presenting relatively short and largely out of context segments of talk is to illustrate how sexist ideology may inform interactions 
of heterosexual couples, not to claim that the observed dynamics are representative or typical among these or other couples. Throughout the article, we will be naming the GPIPs/GHIPs model a "feminist-discursive" perspective and will be contrasting it with a generic systemic perspective. Although we do not use the term "systemic" to refer to the GPIPs/GHIPs model, we acknowledge that the model is systemic. Indeed, we would argue that what makes it distinct when compared to many other feminist and postmodern approaches to family therapy is the explicit retention of systemic premises, particularly the notion of circularity or the idea that family members' actions are mutually reinforcing, and that sequences of actions recur (Bateson 1972; Selvini et al. 1980). Feminists have long critiqued systemic concepts for obscuring therapists' attention to gender issues (e.g., Goldner 1985; Hare-Mustin 1978) and, not surprisingly, many in the field have abandoned these concepts. Some in the field (e.g.,

Cottone and Greenwell 1992; Scheel and Ivey 1998; Terry 1992), including the proponents of GPIPs/GHIPs model, have argued that the concept of circularity can be used not as a way to conceal power discrepancies but as a means of challenging inequalities.

\section{Results}

The Dynamics of Domestic Labour

The first excerpt illustrates partners raising and negotiating issues about the allocation of domestic tasks and caring for children. The partners had separated following the male partner's affair. The partners were now back together and wanted to explore issues that had led to their separation (E-Emma, J—Jack, T—therapist): 


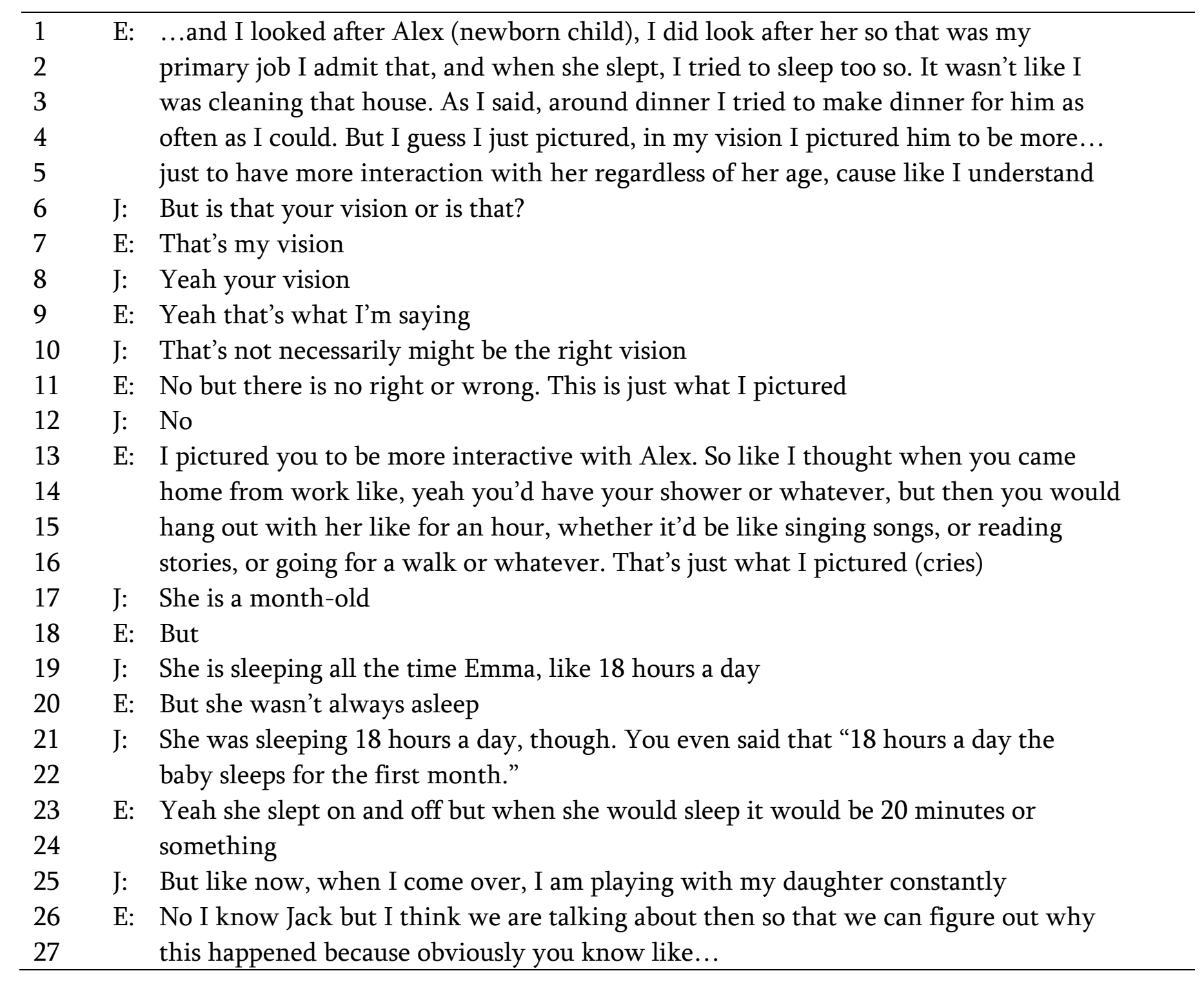


Taking a systemic lens, the couple's interaction might be described as a criticism/defensiveness pattern (Fig. 1), wherein Emma accuses Jack of being absent as a father and Jack defends his non-involvement in childcare. A hypothetical HIP in this case may be Emma selectively noticing Jack's involvement in childcare coupled with his spontaneous efforts to assume childcare responsibilities.

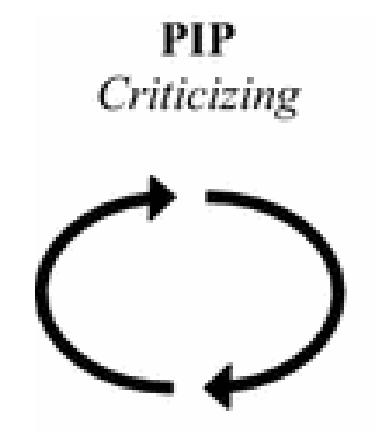

Defending

\section{HIP}

Selective noticing and acknowledging

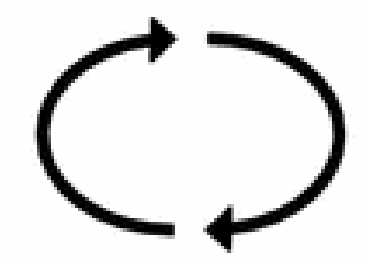

Performing more acts of competence

Fig. 1. HIP \& PIP. Adapted from Tomm (2014b, pp. 20, 24)

The systemic PIPs/HIPs model can be a useful conceptual tool for therapists to recognize how partners' responses comprise a PIP and offer possible entry points for helping the couple transform their interaction. Systemic therapists would facilitate change by eliciting different kinds of responses from the partners, for example, by inviting Emma to reflect and comment on the times when Jack was domestically involved, instead of critically amplifying when he was absent (Tomm 1991, 2014b). We would argue, however, that when interactions and systemic therapy practices are rendered gender-neutral, they may be counterproductive from a political (and therapeutic) standpoint and might hinder the partners' renegotiation of their relationship. Systemic therapists risk reinforcing Emma's responsibility for home and childcare by placing her in the position of "being the primary 
person to hold her partner accountable, making it [his dominance] her responsibility" (Schultz Hall and Sametband 2014, pp. 160-161, italics in the original). Inviting Emma to appreciate Jack's childcare involvement may also present her caring labor as an obligation and his labor as a gift or favor that requires special recognition and acknowledgement (Wood 2011).

Mindful of these limitations of a systemic framework, we wish to emphasize the importance of attending to how family interactions are not only circularly but also politically structured. There are structural constrains on interpersonal negotiations of domestic labor, including gendered ideologies and disparities in opportunities and resources (Bartkowski 1999; Hochschild 1989). Men have individual and collective stakes in distancing themselves from the housework and allocating it to women. Historically, marriage and the domestic labor contract contributed to excluding white, middle class women from the public sphere of life and positioned their white, middle class male partners as those who could and should receive the social and economic benefits of the public sphere, without being responsible for household labor (Delphy and Leonard 1992; McMahon 1999). While these gendered ideologies did not extend to racialized groups or the working classes, women and men from all social locations were expected to adhere to gendered divisions of labor at home. Current research suggests that despite structural shifts leading to women's increased participation in paid work across race, class, nation, and other social variables in an era of neoliberal capitalism, the gendered division of household labor has not shifted very much for families in North America and transnationally (Lan 2003; Thébaud 2010; Yodanis and Lauer 2014)_ although some research suggests otherwise (Hoang and Yeoh 2011). 
Without explicitly analyzing power, systemic therapists might miss how women's historical and ideological subordinate status vis-à-vis men may disadvantage them in determining and negotiating labor arrangements.

Exploring how a criticism-defensiveness sequence of actions is gendered might open up new possibilities for renegotiating the couple relationship. We can discern the following GPIP: Jack minimizes his domestic involvement and Emma compensates for his non-involvement and overlooks her own career or life opportunities. A therapeutic antidote to this pattern could be: Jack participates equally in childcare and perhaps, if economically possible, takes a leave of absence from paid work to experience childcare as primary caregiver and Emma explores career and other opportunities outside of home (Fig. 2). These patterns operate in couple relationships through both partners' representations of labor and their enactments of specific tasks and subjectivities.

Gendered PIP

Men prioritizing their career while minimizing contributions to family life as partners and fathers

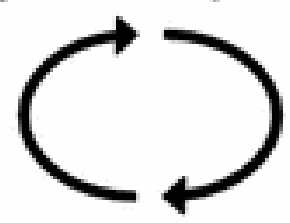

Women covering for men's lack of availability and neglecting their own opportunities and career development

\section{Gendered HIP}

Men supporting women accessing opportunities by taking initiative to participate equally in home tasks

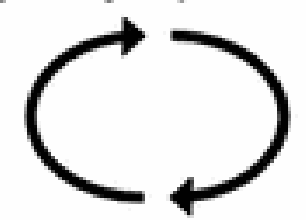

Women attending to their professional development and encouraging and supporting men connecting with their children

Fig. 2. Gendered HIP \& PIP. Adapted from Schultz Hall and Sametband (2014, p. 159)

The interaction has clear traces of a GHIP, noticeable in the partners' efforts to renegotiate childcare responsibilities so that arrangements reflect the needs and preferences of both partners. In particular, Emma invites 
Jack into sharing childcare responsibilities (lines 4-5, 14-16) and Jack demonstrates greater father involvement and performance of non-dominant forms of masculinity (lines 25-26). Despite these markers of greater gender equality, the couple's interaction seems to reflect and perpetuate ideological obstructions to women standing on equal ground with men in the household (and economy). In this excerpt, we notice the following sexist assumptions concerning gender:

1. Caring labor is inherently women's (and not men's) work;

2. Caring labor is minimal and insignificant.

The first assumption is maintained through the construction and enactment of gender-differentiated roles, specifically the allocation of childcare responsibilities to women and away from men. The second premise operates whenever labor is exploited. The issue is not that men devalue women's labor or fail to see its usefulness; rather, labor is necessarily constituted as worthless or invisible in order for exploitation to occur (Delphy and Leonard 1992). Even though the discussion concerns care that is provided to children, it involves services that are used by men, given that they are not held responsible for doing their share of care work (Delphy and Leonard 1992).

Although Emma appears to contest gender inequality and unequal distribution of childcare responsibilities, upon a closer look, the dominant gender order, with its strict gendered divisions of labor, is reinforced. Jack's absence as a father troubles Emma not because it means she needs to compensate by becoming the sole caregiver and neglecting her own career opportunities, but because it negatively affects the baby. It is the baby's 
needs that are centered in her talk. Subjected to the discourse of maternal responsibility, Emma is constituted as a certain kind of subject-the childcare provider (lines 1-2, 4-5, 13-16, 20-24). She assumes the subject position of an "expert" on the baby's behaviors and needs, including the kind of fathering the baby requires, indirectly assessing Jack's father involvement as inadequate or insufficient (lines 4-5, 13-16, 20-24). In accounting for his absence, Jack invokes the baby's age (lines 17, 19, $21-$ 22). The baby being "a month-old" (line 17) offers a range of cultural inferences not only about developmental needs of newborns but also about what caregiving at this early age entails. The upshot of the baby being a month-old is subsequently explicated (line 19: she is sleeping all the time Emma, like 18 hours a day), indirectly presenting any caregiver's involvement with a newborn as largely unnecessary. The child's age does not excuse Emma from caregiving (lines 1-2); if anything, it may reinforce these responsibilities if we consider broader moralizing discourses around maternal attachment with newborns. This justification seems to minimize or take for granted the significant effort that goes into caring for a newborn. It may be seen as both a reflection of Jack's privileged position and a tactic to further support male entitlement to be excused from childcare.

\section{Re-Production of Normative Gender/Sexuality}

The next extract, taken from a therapy session involving another heterosexual couple, helps further illustrate how it may be possible to locate gendered interactions in a segment of talk. The discussion is focused on decision-making concerning what happens in their sexual interactions (C—Claire, B-Bill, T-therapist): 


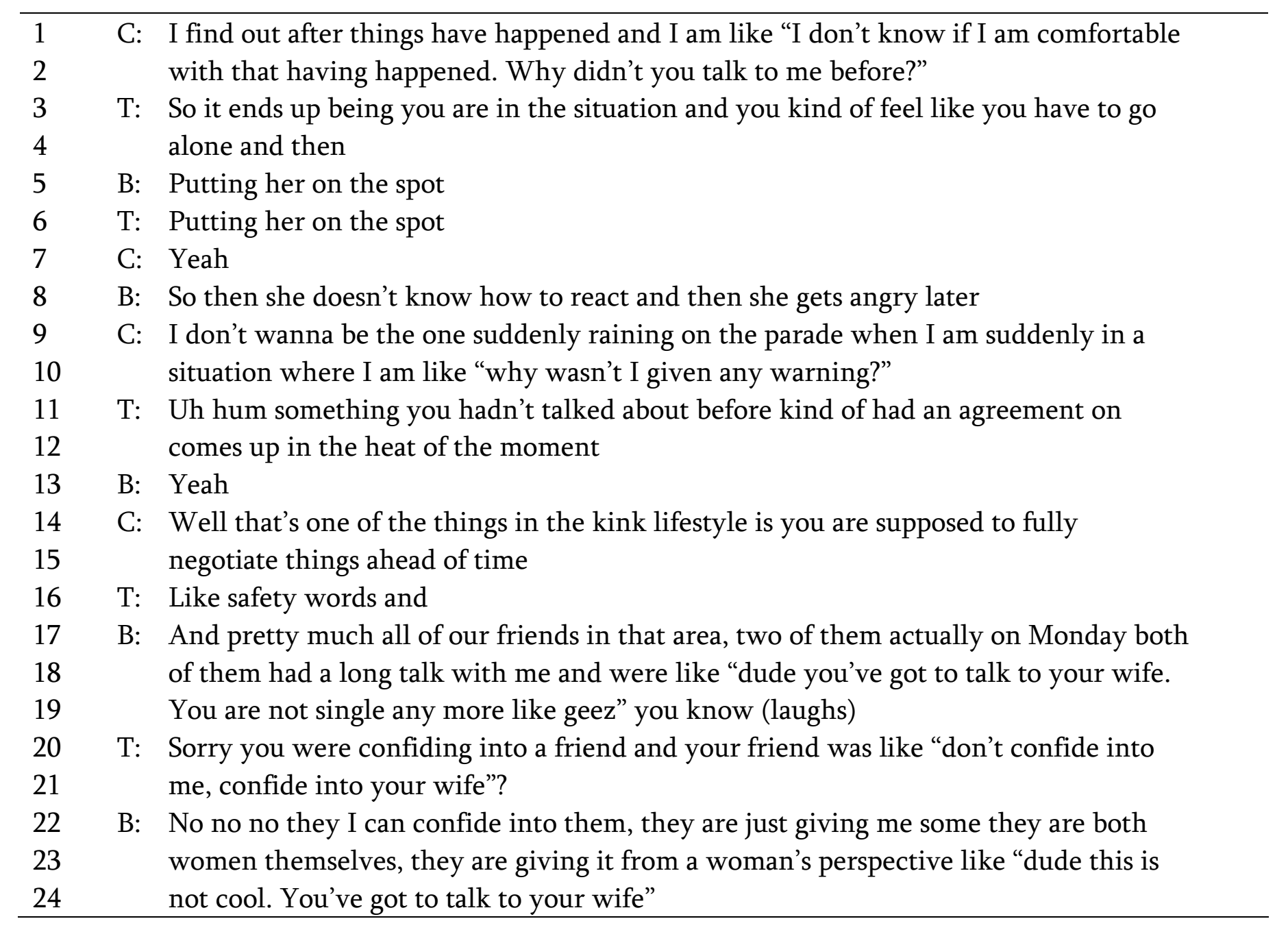


The couple seems to be similarly engaged in the pattern of criticizing coupled with defending (Fig. 1), wherein Claire blames Bill for disregarding her wishes and preferences in their sexual interactions (lines 1-15), while Bill defends his actions by attributing the problem to Claire's failure to assert her wishes in the moment (line 8). A healing alternative could be Claire acknowledging Bill's efforts to honor her sexual preferences coupled with Bill involving Claire in the decision-making concerning their sexuality. Another PIP/HIP can be discerned, as captured in Fig. 3 below (Tomm 2014b, p. 31).

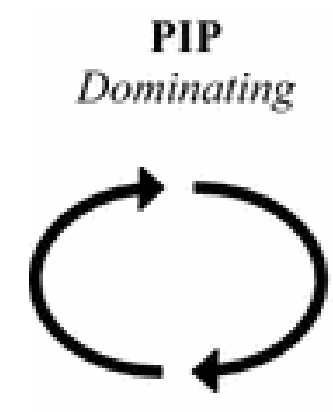

Submitting

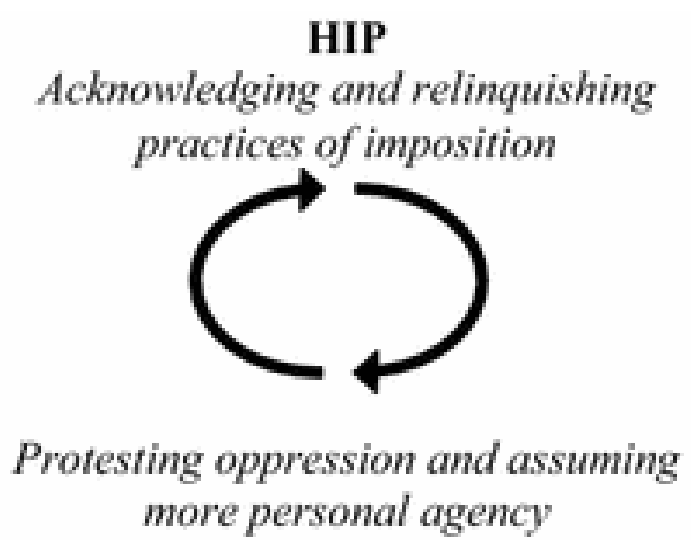

more personal agency

Fig. 3. HIP \& PIP. Adapted from Tomm (2014b, p. 31)

Although a systemic perspective is a valuable therapeutic tool, we would argue that the partners' interactions are better described through a systemic/feminist lens that considers each partner's socially constituted and circularly reinforced differential positioning within the family and society. This way, PIPs/HIPs are not neutral with respect to gender and sexuality but are informed by and re-produce these dimensions of social difference and associated gendered and sexual power relations. The couple describes a recurrent gendered PIP, wherein Bill imposes his sexual wishes on Claire and fails to elicit her consent and Claire submits to his 
desires and dismisses her sexual preferences. A GHIP, in this case, would involve the partners assuming resistant subject positions and exploring nonnormative ways of constituting themselves as sexual and gendered beings. Specifically, it would entail Bill honoring Claire's sexual preferences and Claire protesting imposition and voicing her discomfort (Fig. 4).

Gendered PIP

Men imposing their sexual preferences and marginalizing women's preferences

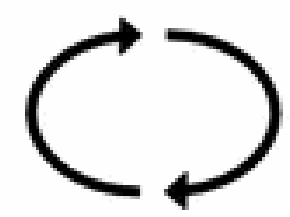

Women submitting and dismissing their own sexual preferences
Gendered HIP

Men acknowledging and making amends for imposition and eliciting women's sexual consent and preferences

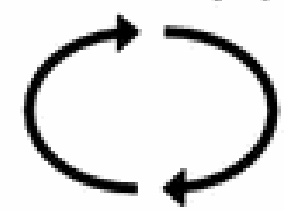

Women protesting imposition and voicing their sexual preferences

Fig. 4. Gendered HIP \& PIP. Adapted from Schultz Hall and Sametband (2014, p. 158)

On the surface, the GPIP and GHIP seem identical to the PIP and HIP presented in Fig. 3. Interpersonal patterns are gendered not because of the gender of actors but because of the participants' (mutual) reliance on what Butler (1990) calls the "heterosexual matrix," an ideology that differentiates people into two opposite sexes with distinct gendered qualities, naturalizes erotic attraction for the "other" gender/sex, and positions one side of the matrix (women-feminine-queer) as inferior to the other (men-masculine-heterosexual). This compulsory heterosexist/heteronormative ideology can be used to justify and legitimize male privilege and dominance, reaffirm the superiority of masculinity over femininity, reinscribe heterosexuality as natural and normal, and position certain nonnormative expressions of sexuality (including kink) as queer. Butler (1990) notes that while destabilizing sexism and heterosexism, 
individuals' nonnormative sexual practices and transgressive gender performances do not necessarily disrupt gendered power and the reproduction of dominant-subordinate relationships.

While in some respects both partners seem to initiate a GHIP and transgress hegemonic masculinity and submissive femininity by acknowledging imposition (line 5) and protesting it (lines 2, 10, 14-15), this stretch of talk is also indicative of a subordination-supporting GPIP. Such a pattern is based on often-twinned discourses of male sexual drive and female passivity, as well as that of male aggressiveness and conquest (Gavey 2005; Hare-Mustin 1994; Hollway 1998). These discourses advance the following sexist and heterosexist premises:

1. Men are subjects possessing sexual drive that need to be gratified.

2. Women are objects and passive recipients of the male drive; they are defined and used by men (as sexual objects) in ways that benefit men as a group.

3. Men and women are opposite sexes who acquire distinct masculine and feminine gender identities and experience sexual desire only for the "other" sex, thus affirming the naturalness and normalcy of heterosexuality.

The partners seem to simultaneously accommodate and resist the subject/object positions offered by these discourses. Bill's sexual wishes are prioritized in his partner's constructions of their sexual relations. Claire is presented as focused on ensuring that she does not disrupt Bill's sexual initiatives (I don't wanna be the one suddenly raining on the parade) and as 
lacking agency, voice, and awareness of her own sexual preferences during sex (I find out after things have happened and I am like "I don't know if I am comfortable with that having happened"). While Claire assumes the position of a passive recipient of Bill's sexual drive or de-personalized object with no desires or wishes of her own, Bill is constituted as its subject who moves forward in a sexual encounter without considering his partner's preferences. Importantly, this occurs despite the couple's involvement in kink and Bill's knowledge of the higher standards of consent and safety followed by this community. Bill's failure to involve Claire in decisionmaking around sexuality is presented as residual of his singlehood or him "by nature" not knowing how to take another person into account (lines 1724). Eliciting another's sexual consent is presented as a foreign practice, something that men need to be educated about (by women; lines 17-24), even in a countercultural context where sexual consent is treated as something that must be explicitly and continuously negotiated and given. The notion that men are inherently self-centered normalizes male dominance or presents it as a common or typical male practice, exempting men from accountability.

\section{Disabled Masculinity}

The following excerpt illustrates the intersection of gender and disability. The session is focused on exploring the impact of Mark's unemployment and minimal contributions at home on Nancy and on the couple's relationship ( $\mathrm{N}-\mathrm{Nancy}, \mathrm{M}-$ Mark, T-therapist): 
doing all of these things or asking you questions to pull out where you wanna go, where is your focus?

M: I don't think I had any um

N: Till Monday night

M: Yes I till Monday night, I sat her down and talked about, and thought about it... But yeah I just decided to go ahead and change a bit and for the better anyway so

T: Right

$\mathrm{N}$ : I think what we've discussed was cause we had a fight on Sunday night ...

$\mathrm{N}$ : But I think we decided that since he is seeing a surgeon July 15, maybe now right now right this minute looking for a job is not good, cause we don't know what's gonna happen with that appointment. But in the meantime he does not have to sit in front of the damn TV 24/7. I am at school, how about you be the housewife, you do the dishes, you make dinner, you know like there is some cleaning that needs to be done. There is lots of stuff in the house that needs to be out of the house, go through it, get rid of it. Find things that aren't sitting in front of the TV, and so we've had a few nights where the TV's been off and we've been in peace

T: So what's the underlying message? I feel like whatever it is it's really important. Yeah I am hearing "change," I am hearing "don't watch the TV so much, help out"

$\mathrm{N}$ : The underlying message I think is that we are absolutely stuck and I feel trapped in a relationship that I don't want to be in because I've been here before. I've put in 5 weeks, and then 10 years to get back a piece of that 5 weeks. I am doing it again. I am repeating that pattern, I don't want to do that

T: It sounds like that's your message. What's the message for Mark?

$\mathrm{N}$ : The message for Mark is that he's stuck, he's stuck. And he is stuck in "he is disabled." In his mind he is disabled so he can't do anything. And I needed to point out to him that that's not quite as true cause there are a lot of things that he can do. I 
mean he is not as disabled as he had let his mind push him to thinking like "this is all I can do, I can walk, I can watch TV." 
A systemic sketch of this exchange looks like this: Nancy blaming and diminishing Mark coupled with Mark blaming and diminishing himself. An antidote to this pattern would be Nancy affirming and crediting Mark coupled with Mark affirming and crediting himself (Tomm 2014b, p. 31, see Fig. 5).

PIP Blaming and diminishing the other

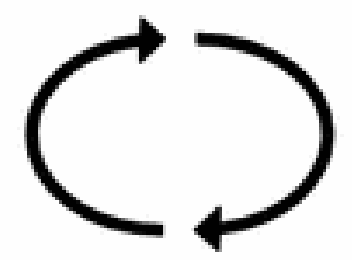

Blaming and diminishing the self
HIP

Affirming and crediting the other

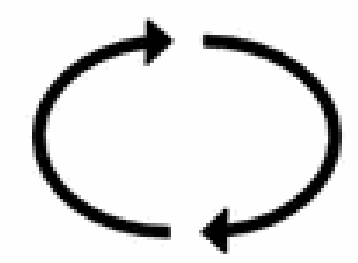

Affirming and crediting the self

Fig. 5. HIP \& PIP. Adapted from Tomm (2014b, p. 31)

A systemic perspective on this interaction would frame Nancy's reactions as contributing to relational pathology. This is in contrast to a feminist perspective, which would frame her reactions as potentially helpful expressions of political protest aimed at renegotiating relational arrangements to better reflect preferences of both partners (e.g., Brown 1994). The HIP may also be problematic from a feminist perspective. It may reinforce gender inequalities by implicitly affirming men's entitlement to not be more involved domestically or by presenting men's domestic contributions as deserving special recognition and appreciation. A feminist discursive therapist may focus on the gendered dynamics of power, namely Nancy taking on the bulk of domestic and nondomestic responsibilities and Mark distancing from household tasks, similar to the first couple's interaction. The GHIP may look like this: Mark enhancing his domestic 
contributions and/or seeking external assistance with domestic tasks coupled with Nancy exploring career and other opportunities outside of home (see Fig. 2 for a GPIP/GHIP).

The excerpt highlights the relevance of disability for the participants and brings to light that "men can be victims, as well as oppressors" (Shakespeare 1999, p. 63). While Mark occupies a dominant position based on gender, he assumes a subordinate position based on disability. Here ableism intersects with sexism and heterosexism to advance a masculine version of corporeal normalcy (Goodley 2014; McRuer 2006). In a sexist and heterosexist culture, prejudice is maintained against unruly, queer, and "leaky" bodies that do not fit the hegemonic conception of embodiment (Panzarino and Clare 2007; Shildrick 1997). Mark's disabled physicality arguably constrains his gender-based access to social status and physical strength (a marker of masculinity and heterosexuality) available to nondisabled heterosexual men (McRuer 2006; Shakespeare 1999). Mark is positioned, in this excerpt, as an inadequate partner who is not pulling his weight. His inactivity and disability threaten the dominance of the heterosexual binary (active/male and passive/female) and trouble his status as a man. He is encouraged to transcend disability to retain his desirability as a heterosexual partner (lines 13-18, 21-24, 26-30). Indirectly, interlocutors advance a construction of ideal masculinity that hinges on an able-bodied male partner who is able to contribute in material and nonmaterial ways toward the relationship. Mark aligns with this version by positioning himself as working toward his presupposed "normal" role as worker and provider in the relationship (lines 6-7, 17-18). Nancy draws upon a relational framing to advance this construction of masculinity by 
suggesting that if Mark were to transcend his disability, it would help to improve or preserve the relationship (lines 18, 21-22). In so doing, she maintains a relationally-oriented position, in line with traditional notions of "proper" femininity.

Mark's self-attributed membership in the category "disabled" arguably does not erase his accountability for gender inequalities. Under contemporary neoliberal capitalism, responsibility for care work and social reproduction is downloaded onto women in North American households and coded as feminine, regardless of whether women work outside the home or men do paid work (Lan 2003; Thébaud 2010; Yodanis and Lauer 2014). Nancy's utterance "I am at school, now you be the housewife" (lines 12-13), while appearing to challenge gender-differentiation, subtly reinforces it. She claims it is now her turn to assume the "breadwinner" slot in family relations and for Mark (by virtue of his inability to act like a "man") to become a "housewife." While roles are reversed, the binary of feminine/devalued and masculine/valued labor is sustained. The sexist assumption resembles that identified in excerpt 1: domestic/unpaid labor belongs to women (or those failing to act like "real men"). The couple's conflict points to the urgent need for more drastic changes in the political economy to revalue care work. As a temporary, micro-level solution, the couple could be supported in transforming the GPIP by inviting Mark to contribute more to the domestic sphere of life and Nancy in distancing more from domestic responsibilities and tasks. Also, rather than mobilizing the disabled person to contribute to the household, a therapist might invite the couple to investigate household tasks that could be completed through state-funded disability support programs, if such programs are available in 
their area (e.g., cooking, yard work, personal care) and might open up conversations about the devaluing and feminizing of care work in society.

\section{Discussion}

In this study, we used Foucauldian discourse analysis to examine how gendered power is circularly reproduced or generated through recurrent patterns of interaction in the context of couple therapy. The analysis shows that gender inequalities identified by feminists in the 1970s, including unwanted sex and exploitation of women's domestic labor, still take place within Anglo-Western heterosexual relationships (Jackson 2001). We identified gendered discourses and assumptions supporting partners' positions in subordination-supporting patterns of interaction. Such discourses can manifest, for instance, in constructions that center women's caregiving functions and overlook non-dominant femininities and relational arrangements. Concurrently with identifying practices of power, we also noted practices of resistance or how partners depart from and rearticulate prevalent cultural conceptions of gender and intimate relations. We distinctly infused FDA with a systemic lens to explore how family members may be reciprocally positioned or constituted in specific ways by societal discourses, for example, as subjects or objects of the male sex drive. The form gender takes is constituted and adjusted not only to a broader historical moment but also to a more immediate moment of interaction; it is grounded in and responsive to the interlocutor's actions in their interaction. A systemic lens thus helped us to identify not only how sociocultural resources inform and constrain clients' subjectivities and relations, but also how cultural meanings are taken up in reciprocal and mutually reinforcing ways (e.g., how dominance invites subordination and visa versa). Due to 
the lack of an explicit theory of gendered oppression within a systemic framework, systemic therapists are not well equipped to notice and challenge gender oppression and inequality. By overfocusing on systemic dynamics at the expense of broader sociocultural forces, therapists risk pathologizing partners' responses or introducing politically questionable interventions. At the same time, a systemic perspective integrated with a feminist/discursive lens can clarify how dominance and oppression become "coupled" or reinforced through interaction. We thus advocate the infusion of feminist and discursive perspectives into systemic practice.

The question of who is morally responsible (and non-responsible) for relational inequalities and minimizing them warrants brief discussion. Would therapists adopting this model focus on supporting men in acting more accountably or would they attribute responsibility to both partners, in line with the systemic principles of neutrality and circularity? In working with these couples, as systemic-discursive therapists, we would simultaneously support men in enhancing their sense of accountability and explore how both parties contribute to the maintenance of a sexist order. We would also assume a dual (partial and multi-partial) stance in working with these couples (Anderson 1997; Tomm 1984). In assuming a partial or feminist stance, in these instances we would align with women. We would do this not because of their subordinate standing in a family and in society, but because they happened to be the ones who challenged a sexist order and advanced egalitarian morality. At the same time, we would position ourselves multi-partially or systemically vis-à-vis all moral standards and constructions of roles and identities featuring in interaction. In being multipartial we would strive to be "slow" in resorting to, and interactionally 
advancing, our feminist moral standards and would try to create space for multiple meanings concerning "proper" partner conduct.

We hope that in writing this article we contribute to the advancement of critical/feminist discursive inquiry in family therapy (for a review of existing studies see Avdi and Georgaca 2007; Tseliou 2013). We encourage family therapists to use a feminist-discursive lens and family therapy scholars to employ critical/feminist discursive methods of inquiry. Overall, we highlight the salience of gender in family therapy practice and scholarship. We have demonstrated how a systemic lens alone is insufficient for clarifying how dominant or normative gender and gender inequalities may be re-produced in everyday couple interactions, including in the therapeutic context. A systemic perspective may need to be augmented with a feminist/discursive perspective that attends to discourse, in particular gendered discourses and assumptions informing partners' actions and interactions, in and outside of therapy (e.g., Dickerson 2013; Knudson-Martin et al. 2015). From a discursive perspective, discourse constitutes subjects and social relations suitable to neoliberal, patriarchal, and other governmentality (Foucault 1991b) rather than neutrally expressing "real" and pre-formed (i.e., formed prior to social interaction) gender and family relations. A discursive lens can assist therapists in noticing how discourse turns people into subjects (e.g., caregivers, objects of the other's sexual desire) or subjects them to the operations of power (Miller 2008). Gendered discourses constitute people into "men" and "women," attributes distinct qualities and abilities to each group, and positions them as hierarchically related. Discursive methods of inquiry can show how people are subjected to the operations of gendered power 
through their everyday embodied conduct and interaction and routine uptake of discourses and cultural meanings concerning gender. As aforementioned, people are not passive or completely lacking agency in this process; rather, they actively draw on, make use, and modify "broader" cultural meanings and prescriptions (e.g., Buttler 2004).

To adequately prepare the next generation of family therapists, it is important to highlight how they might recognize the multiple, complex, and intersecting ways in which gender and gendered power and ideology permeate their work. Given that societal patterns of domination are largely taken-for-granted by therapists and families alike (Hernández et al. 2005; Knudson-Martin 2013), practitioners need better tools to recognize them. Studies using FDA could offer therapists guidance around what to pay attention to and how to recognize practices of power and resistance at work in their interactions with families. Foucault-inspired discursive analyses offer a compelling alternative to conventional binary, uniform, and essentialist readings of gender by highlighting the complexity and intersectionality of gender and the constitutive role of discourse; that is, how discourse constructs and maintains gender differences and hierarchies. Such analyses provide a unique perspective on the family and family therapy as social institutions involved in the reproduction of certain subjects and relations, including the regulatory and constructive role of therapists in reinforcing gendered ideology and power (Avdi and Georgaca 2007). The approach can also help identify opportunities for change by making visible efforts that family members take to transgress and transform cultural prescriptions. 
In recent years, family therapists have made concerted efforts to unsettle gendered patterns and inequities within families. Nonetheless, there is a need for more work that provides answers to questions about how the dynamics of power are perpetuated in families and how to support clients in achieving greater equality. Discursive analyses like the one we presented can help foster critical consciousness, accountability, and empowerment among family therapists (Hernández et al. 2005) and stimulate therapeutic and social change.

\section{Acknowledgements}

The authors would like to thank clients and therapists, and other individuals, who helped develop the archive of therapy sessions used in this article. This work was supported by funding from the Canada Foundation for Innovation (CFI) and the Social Sciences and Humanities Research Council of Canada (SSHRC).

\section{Compliance with Ethical Standards Conflict of interest}

The authors declare that they have no conflict of interest.

\section{References}

Almeida, R., Dolan-Del Vecchio, K., \& Parker, L. (2008). Transformative family therapy: Just families in a just society. Boston, MA: Pearson.

American Psychiatric Association (APA). (1980). Diagnostic and statistical manual of mental disorders (3rd ed.). Washington, DC: American Psychiatric Association. 
Anderson, H. (1997). Conversation, language, and possibilities: A postmodern approach to therapy. New York, NY: Basic Books.

Anthias, F. (2012). Intersectional what? Social divisions, intersectionality and level of analysis. Ethnicities, 13(1), 3-19. doi: 10.1177/1468796812463547.

Arribas-Ayllon, M., \& Walkerdine, V. (2008). Foucauldian discourse analysis. In C. Willig \& W. Stainton-Rogers (Eds.), The SAGE handbook of qualitative research in psychology (pp. 91-109). London: Sage.

Avdi, E., \& Georgaca, E. (2007). Discourse analysis and psychotherapy: A critical review. European Journal of Psychotherapy and Counselling, 9(2), 157-176. doi: 10.1080/13642530701363445.

Bartkowski, J. P. (1999). One step forward, one step back: "Progressive traditionalism" and the negotiation of domestic labor in evangelical families. Gender Issues, 17(4), 37-61. doi: 10.1007/s12147-998$\underline{0003-3}$.

Bateson, G. (1972). Steps to an ecology of mind. New York, NY: Ballantine.

Boden, D., \& Zimmerman, D. H. (Eds.). (1991). Talk and social studies in ethnomethodology and conversation analysis. Cambridge: Polity.

Brown, L. S. (1994). Subversive dialogues: Theory in feminist therapy. New York: Basic Books. 
Butler, C. (2015). Intersectionality in family therapy training: Inviting students to embrace the complexities of lived experience. Journal of Family Therapy, 37(4), 583-589. doi: 10.1111/1467-6427.12090.

Butler, J. (1990). Gender trouble: Feminism and the subversion of identity. New York, NY: Routledge.

Butler, J. (1993). Bodies that matter: On the discursive limits of "sex". New York, NY: Routledge.

Butler, J. (2004). Undoing gender. New York: Routledge.

Christensen, A., \& Jensen, S. Q. (2012). Doing intersectional analysis: Methodological implications for qualitative research. NORA—Nordic Journal of Feminist and Gender Research, 20(2), 109-125. doi: $\underline{10.1080 / 08038740.2012 .673505}$.

Cole, E. R. (2009). Intersectionality and research in psychology. American Psychologist, 64, 170-180. doi: $10.1037 / a 0014564$.

Collins, P. H. (1990). Black feminist thought: Knowledge, consciousness, and the politics of empowerment. New York, NY: Routledge.

Connell, R. W., \& Messerschmidt, J. (2005). Hegemonic masculinity: Rethinking the concept. Gender and Society, 19, 829-859. doi: 10.1177/0891243205278639.

Cottone, R. R., \& Greenwell, R. J. (1992). Beyond linearity and circularity: Deconstructing social systems theory. Journal of Marital and Family Therapy, 18(2), 167-177. doi: 10.1111/j.1752-0606.1992.tb00927.x. 
Crenshaw, K. (1991). Mapping the margins: Intersectionality, identity politics, and violence against women of color. Stanford Law Review, 43, 1241-1299. doi: $10.2307 / 1229039$.

Davies, B., \& Harré, R. (1999). Positioning and personhood. In R. Harré \& L. van Lagenhove (Eds.), Positioning theory: Moral contexts of intentional action (pp. 32-52). Malden, MA: Blackwell.

Delphy, C., \& Leonard, D. (1992). Familiar exploitation: A new analysis of marriage in contemporary western societies. Oxford: Polity.

Dickerson, V. C. (2013). Patriarchy, power, and privilege: A narrative poststructural view of work with couples. Family Process, 52, 102 114.

Edwards, D. (1998). The relevant thing about her: Social identity categories in use. In C. Antaki \& S. Widdicombe (Eds.), Identities in talk (pp. 1533). London: Sage.

Fairclough, N. (2012). Critical discourse analysis. In P. Gee \& M. Handford (Eds.), The Routledge handbook of discourse analysis (pp. 9-20). New York, NY: Routledge.

Fairclough, N., Mulderrig, J., \& Wodak, R. (2011). Critical discourse analysis. In T. A. van Dijk (Ed.), Discourse studies: A multidisciplinary introduction (2nd ed., pp. 357-378). London: Sage. 
Foucault, M. (1972). The archaeology of knowledge and the discourse on language (A. M. Sheridan-Smith, Trans.). New York, NY: Pantheon Books.

Foucault, M. (1982). Afterword: The subject and power. In H. L. Dreyfus \& P. Rabinow (Eds.), Michel Foucault: Beyond structuralism and hermeneutics (pp. 208-226). Brighton: Harvester.

Foucault, M. (1991a). Discipline and punish: The birth of the prison (A. M. Sheridan, Trans.). London: Penguin.

Foucault, M. (1991b). Governmentality. In G. Burchell, C. Gordon, \& P. Miller (Eds.), The Foucault effect: Studies in governmentality (pp. 87104). Hemel Hempstead: Harvester Wheatsheaf.

Gavey, N. (2005). Just sex?: The cultural scaffolding of rape. New York, NY: Routledge.

Giddens, A. (1979). Central problems in social theory: Action, structure and contradiction in social analysis. Los Angeles, CA: University of California Press.

Goldner, V. (1985). Feminism and family therapy. Family Process, 24, $31-$ 47. doi: $10.1111 / j .1545-5300.1985 .00031 . x$.

Goodley, D. (2014). Dis/ability studies: Theorising disablism and ableism. London: Routledge.

Hare-Mustin, R. T. (1978). A feminist approach to family therapy. Family Process, 17(2), 181-194. doi: 10.1111/j.1545-5300.1978.00181.x. 
Hare-Mustin, R. T. (1994). Discourses in the mirrored room: A postmodern analysis of therapy. Family Process, 33, 19-35. doi: 10.1111/j.15455300.1994.00019.x.

Hare-Mustin, R. T., \& Marecek, J. (1990). Making a difference: Psychology and the construction of gender. New Haven, CT: Yale University Press.

Hernández, P., Almeida, R., \& Dolan-Del Vecchio, K. (2005). Critical consciousness, accountability, and empowerment: Key processes for helping families heal. Family Process, 44, 105-119. doi: 10.1111/j.1545-5300.2005.00045.x.

Hoang, L. A., \& Yeoh, B. S. (2011). Breadwinning wives and "left-behind" husbands: Men and masculinities in Vietnamese transnational family. Gender and Society, 25(6), 717-739. doi: 10.1177/0891243211430636.

Hochschild, A. R. (1989). The second shift: Working parents and the revolution at home. New York, NY: Viking.

Hollway, W. (1998). Gender difference and the production of subjectivity. In J. Henriques, W. Hollway, C. Urwin, C. Venn, \& V. Walkerdine (Eds.), Changing the subject: Psychology, social regulation, and subjectivity (2nd ed., pp. 227-263). New York, NY: Routledge.

Ingraham, C. (2006). Thinking straight, acting bent: Heteronormativity and homosexuality. In K. Davis, M. Evans, \& J. Lorber (Eds.), Handbook of gender and women's studies (pp. 307-321). London: Sage. 
Jackson, S. (2001). Why a materialist feminism is (still) possible-and necessary. Women's Studies International Forum, 24(3/4), 283-293. doi: 10.1016/S0277-5395(01)00187-X.

Keenan, E. K. (2007). Patterns of interaction. Smith College Studies in Social Work, 77(1), 69-88. doi: 10.1300/J497v77n01 04.

Knudson-Martin, C. (2013). Why power matters: Creating a foundation of mutual support in couple relationships. Family Process, 52, 5-18. doi: 10.1111/famp.12011.

Knudson-Martin, C., et al. (2015). Competencies for addressing gender and power in couple therapy: A socio emotional approach. Journal of Marital and Family Therapy, 41(2), 205-220. doi: 10.1111/jmft.12068.

Lan, P. (2003). Maid or madam? Filipina migrant workers and the continuity of domestic labor. Gender and Society, 17(2), 187-208. doi: 10.1177/0891243202250730.

Lazar, M. M. (2005). Politicizing gender in discourse: Feminist critical discourse analysis as a political perspective and praxis. In M. M. Lazar (Ed.), Feminist critical discourse analysis: Gender, power, ideology in discourse (pp. 1-30). New York, NY: Palgrave Macmillan.

McCall, L. (2005). The complexity of intersectionality. Signs Journal of Women, Culture and Society, 30(3), 1771-1800. doi: $\underline{10.1086 / 426800 .}$

McDowell, T., \& Hernández, P. (2010). Decolonizing academia: Intersectionality, participation, and accountability in family therapy and 
counseling. Journal of Feminist Family Therapy, 22(2), 93-111. doi: 10.1080/08952831003787834.

McGeorge, C. R., Carlson, T. S., \& Toomey, R. B. (2014). The intersection of spirituality, religion, sexual orientation, and gender identity in family therapy training: An exploration of students' beliefs and practices. Contemporary Family Therapy: An International Journal, 36(4), 497506. doi: $10.1007 / \mathrm{s} 10591-014-9312-8506$.

McGoldrick, M., \& Hardy, K. V. (Eds.). (2008). Re-visioning family therapy: Race, culture, and gender in clinical practice (2nd ed.). New York, NY: Guilford.

McMahon, A. (1999). Taking care of men: Sexual politics in the public mind. New York, NY: Cambridge University Press.

McRuer, R. (2006). Compulsory able-bodiedness and queer/disabled existence. In L. J. Davis (Ed.), The disability studies reader (2nd ed., pp. 88-99). New York, NY: Routledge.

Miller, L. (2008). Foucauldian constructionism. In J. A. Holstein \& J. F. Gubrium (Eds.), Handbook of constructionist research (pp. 251-274). London: Guilford.

Palazzoli Selvini, M., Boscolo, L., Cecchin, G., \& Prata, G. (1980). Hypothesizing-circularity-neutrality: Three guidelines for the conductor of the session. Family Process, 19, 3-12. doi: 10.1111/j.1545-5300.1980.00003.x. 
Panzarino, C., \& Clare, E. (2007). Sexual selves, community allegiance. In

S. B. Mintz (Ed.), Unruly bodies: Life writing of women with disabilities (pp. 93-136). Chapel Hill, NC: University of North Carolina Press.

Parker, I. (1992). Discourse dynamics: Critical analysis for social and individual psychology. New York, NY: Routledge.

Scheel, M. J., \& Ivey, D. C. (1998). Neutrality and feminist perspective: Can they co-exist in family therapy? Contemporary Family Therapy, 20(3), 315-331. doi: 10.1023/A:1022464812469.

Schultz Hall, J., \& Sametband, I. (2014). His cave and her kitchen: Gendered PIPs and HIPs and societal discourses. In K. Tomm, S. St. George, D. Wulff, \& T. Strong (Eds.), Patterns in interpersonal interactions: Inviting relational understandings for therapeutic change (pp. 143-167). New York, NY: Routledge.

Shakespeare, T. (1999). The sexual politics of disabled masculinity. Sexuality and Disability, 17(1), 53-64. doi: 10.1177/1097184X12439879.

Sharp, E. A., \& Keyton, K. (2016). Caught in a bad romance? The negative effect of normative dating and marital ideologies on women's bodies. Sex Roles. doi: 10.1080/10911359.2012.647478.

Shildrick, M. (1997). Leaky bodies and boundaries. Feminism, postmodernism and (bio)ethics. London: Routledge. 
St. George, S., \& Wulff, D. (2014). Braiding socio-cultural interpersonal patterns into therapy. In K. Tomm, S. St. George, D. Wulff, \& T. Strong (Eds.), Patterns in interpersonal interactions: Inviting relational understandings for therapeutic change (pp. 124-142). New York, NY: Routledge.

St. George, S., Wulff, D., \& Tomm, K. (2015). Talking societal discourses into family therapy: A situational analysis of the relationships between societal expectations and parent-child conflict. Journal of Systemic Therapies, 34(2), 15-30. doi: 10.1521/jsyt.2015.34.2.15.

Sunderland, J. (2004). Gendered discourses. New York, NY: Palgrave Macmillan.

Sutherland, O. A., LaMarre, A., Rice, C., \& Hardt, L. (2016). New sexism: Turning to ethnomethodology and membership categorization analysis for help (in preparation)

Terry, L. L. (1992). Gender and family therapy: Adding a bi-level belief systems component to assessment. Contemporary Family Therapy, 14(3), 199-210. doi: 10.1007/BF00901504.

Thébaud, S. (2010). Masculinity, bargaining, and breadwinning:

Understanding men's housework in the cultural context of paid work. Gender and Society, 24(3), 330-354. doi: $\underline{10.1177 / 0891243210369105}$.

Tomm, K. (1984). One perspective on the Milan systemic approach: Part I. Overview of development, theory and practice. Journal for Marital and 
Family Therapy, 10(2), 113-125. doi: 10.1111/j.1752-

0606.1984.tb00001.x.

Tomm, K. (1991). Beginnings of a 'HIPs and PIPs' approach to psychiatric assessment. The Calgary Participator, 1, 21-24. Retrieved from http://www.familytherapy.org/downloads.html.

Tomm, K. (2014a). Introduction: Origins of the PIPs and HIPs framework. In K. Tomm, S. St. George, D. Wulff, \& T. Strong (Eds.), Patterns in interpersonal interactions: Inviting relational understandings for therapeutic change (pp. 1-12). New York, NY: Routledge.

Tomm, K. (2014b). Introducing the IPScope: A systemic assessment tool for distinguishing interpersonal patterns. In K. Tomm, S. St. George, D. Wulff, \& T. Strong (Eds.), Patterns in interpersonal interactions: Inviting relational understandings for therapeutic change (pp. 13-35). New York, NY: Routledge.

Tseliou, E. (2013). A critical methodological review of discourse and conversation analysis studies of family therapy. Family Process, 52, 653-679. doi: 10.1111/famp.12043.

van Dijk, T. A. (2013). Ideology and discourse. In M. Freeden \& M. Stears (Eds.), The Oxford handbook of political ideologies (pp. 1-27). Oxford: Oxford University Press.

Warner, L. R., \& Shields, S. A. (2013). The intersections of sexuality, gender, and race: Identity research at the crossroads. Sex Roles, 68(11-12), 803-810. doi: 10.1007/s11199-013-0281-4. 
Watts-Jones, T. D. (2010). Location of self: Opening the door to dialogue on intersectionality in the therapy process. Family Process, 49, 405-420. doi: 10.1111/j.1545-5300.2010.01330.x.

Weedon, C. (1987). Feminist practice and poststructuralist theory.

Cambridge: Balckwell.

Williams, K., Galick, A., Knudson-Martin, C., \& Huenergardt, D. (2013).

Toward mutual support: $\mathrm{A}$ task analysis of the relational justice approach to infidelity. Journal of Marital and Family Therapy, 39, 285298. doi: $10.1111 / \mathrm{j} .1752-0606.2012 .00324 . x$.

Willig, C. (2013). Foucauldian discourse analysis. In C. Willig (Ed.), Introducing qualitative research in psychology (3rd ed., pp. 129-142). New York, NY: Open University Press.

Winston, E. J., \& Piercy, F. P. (2010). Gender and diversity topics taught in commission on accreditation for marriage and family therapy education programs. Journal of Marital and Family Therapy, 36(4), 446-471. doi: 10.1111/j.1752-0606.2010.00220.x.

Wodak, R., \& Meyer, M. (Eds.). (2016). Methods of critical discourse studies (3rd ed.). London: Sage.

Wood, J. T. (2011). Which ruler do we use? Theorizing the division of domestic labor. Journal of Family Communication, 11(1), 39-49. doi: 10.1080/15267431.2011.534339. 
Wulff, D., St. George, S., \& Tomm, K. (2015). Societal discourses that help in family therapy: A modified situational analysis of the relationships between societal expectations and healing patterns in parent-child conflict. Journal of Systemic Therapies, 34(2), 31-44. doi:

10.1521/jsyt.2015.34.2.15.

Yodanis, C., \& Lauer, S. (2014). Is marriage individualized? What couples actually do? Journal of Family Theory and Review, 6, 184-197. doi: 10.1111/jftr.12038.

Yuval-Davis, N. (2006). Intersectionality and feminist politics. European Journal of Women's Studies, 13, 193-209. doi: 10.1177/1350506806065752. 